Research Article

\title{
Urban Vulnerability Assessment Using AHP
}

\author{
Alireza Rezaei $\mathbb{D}^{1}$ and Sadra Tahsili ${ }^{2}$ \\ ${ }^{1}$ Department of Civil Engineering, Faculty of Engineering, Cyprus International University, Nicosia 99258, Northern Cyprus, \\ Mersin 10, Turkey \\ ${ }^{2}$ Civil Engineering Department, Eastern Mediterranean University, Famagusta, Northern Cyprus, Mersin 10, Turkey \\ Correspondence should be addressed to Alireza Rezaei; arezaei@ciu.edu.tr
}

Received 31 August 2017; Revised 12 December 2017; Accepted 26 December 2017; Published 13 February 2018

Academic Editor: Kirk Hatfield

Copyright (C) 2018 Alireza Rezaei and Sadra Tahsili. This is an open access article distributed under the Creative Commons Attribution License, which permits unrestricted use, distribution, and reproduction in any medium, provided the original work is properly cited.

\begin{abstract}
Purpose. Physical expansion of urban areas and cities is of great importance nowadays. Irreparable damages will thus be caused by lack of proper planning against natural disasters. Crisis management will therefore guide through prevention, preparedness, disaster relief, and recovery by planning an appropriate program. Methodology. Principal processes of crisis management against earthquake in Iran were evaluated and discussed. Multicriteria earthquake crisis management was then proposed by means of Analytic Hierarchy Process (AHP). Vulnerability of 19 urban areas in Qazvin city was studied and analyzed as a case study. Three main criteria were considered as "physical dimensions and physical vulnerability texture," "the amount of urban texture responsibility to aid after crisis," and "possibility of city reversibility after the crisis." These criteria were divided into 20 subcriteria which were prioritized by a questionnaire survey. Findings. "High population density," "urban texture of old and repairable buildings," "lack of relief and medical services," "a few organic texture areas," "sidewalks with less than 6 meters width in the region," and "lack of open spaces in the area" were concluded to be the most important reasons causing high vulnerability of urban texture in Qazvin city.
\end{abstract}

\section{Introduction}

Urban sprawl, urbanization, and the gradual increase in the number of cities are important issues in developing countries. Natural disasters like earthquakes are of the most important matters, especially in countries which are located on earthquake belts such as Iran. The occurrence of natural disasters such as floods, earthquakes, and hurricanes most often have a devastating impact on human settlements and heavy casualties against their inhabitants. Due to their unexpected nature and the need to take quick and correct decisions and actions, the theoretical basis of these decisions has led to a discipline called disaster management. Some main criteria which must be considered in disaster management are proper urban planning, urban land use, connection network, and urban infrastructures, which in turn will greatly reduce the effects and consequences of natural disasters.

Crisis management is a key part of dealing with any crisis arising from natural disasters. Finding appropriate methods and solutions to reduce damages and consequences of earthquakes was always the focus of field scholars. The present study focuses on postearthquake crisis management of the Qazvin city in Iran using Analytical Hierarchy Process (AHP). Qazvin city has high vulnerability facing natural disasters such as earthquake since it is located among the Alborz range of mountains and floodways inside it. Properties of 19 districts of the city were collected and categorized according to various parameters of vulnerability. Three main categories and 20 subcriteria were considered in AHP. To make a binary comparison through subcriteria, a questionnaire survey was performed. Management factors were illustrated via AHP to be considered in planning, preparedness, and relief efforts for the development and reconstruction. Finally, a mathematical model was developed to analyze and evaluate vulnerability of each region of the city.

\section{Principles of Crisis Management}

Challenges of today's cities are not limited only in social, economic, political, and cultural issues, but there are also 




FIgURE 1: Sample organizational and operational system in crisis management.

influential environmental factors that constitute urban context. Experiences from recent earthquakes show that most of damages were due to poor urban planning and failure in complying principles and criteria based on weakness in identification of the factors affecting vulnerability of cities [1-4].

Crisis is a phenomenon created by natural and human events and operations and exerts losses and damages to a group of human beings while its removal needs some emergency and extraordinary operations [5]. Crisis management thus involves continuous and dynamic actions, and in general, it is solidly based on the classical management functions consisting of planning, organizing, execution, leadership, and control. The planning process and actions of public officials and agencies is the observation and critical analysis to prevent the crisis, or if they occur, to attempt to reduce the effects, to get prepared, to react, to relieve rapidly and to recover to achieve normalcy and reconstruction [5].

The most important part of crisis management measures should focus on preventing crisis caused by natural disasters to reduce the risks and vulnerabilities. If we are to consider the crisis management with a broader concept than that of operations after the accident, it includes concepts such as risks reduction, permanent readiness, and meeting specific needs of the accident, including emergency in short term or long term. Since comprehensive planning for city needs much time and cost, it is required to clarify the suburban regions in terms of vulnerability rate and priority in obvious measures and planning [6]. To perform a proper crisis management, the following factors must be carefully investigated and considered [5]:

(i) Likelihood of crisis happening and dangers caused by it

(ii) Existing resources

(iii) Organizational logistics

(iv) Planning shortcomings

(v) Measures required in each cycle of crisis management

(vi) Training 


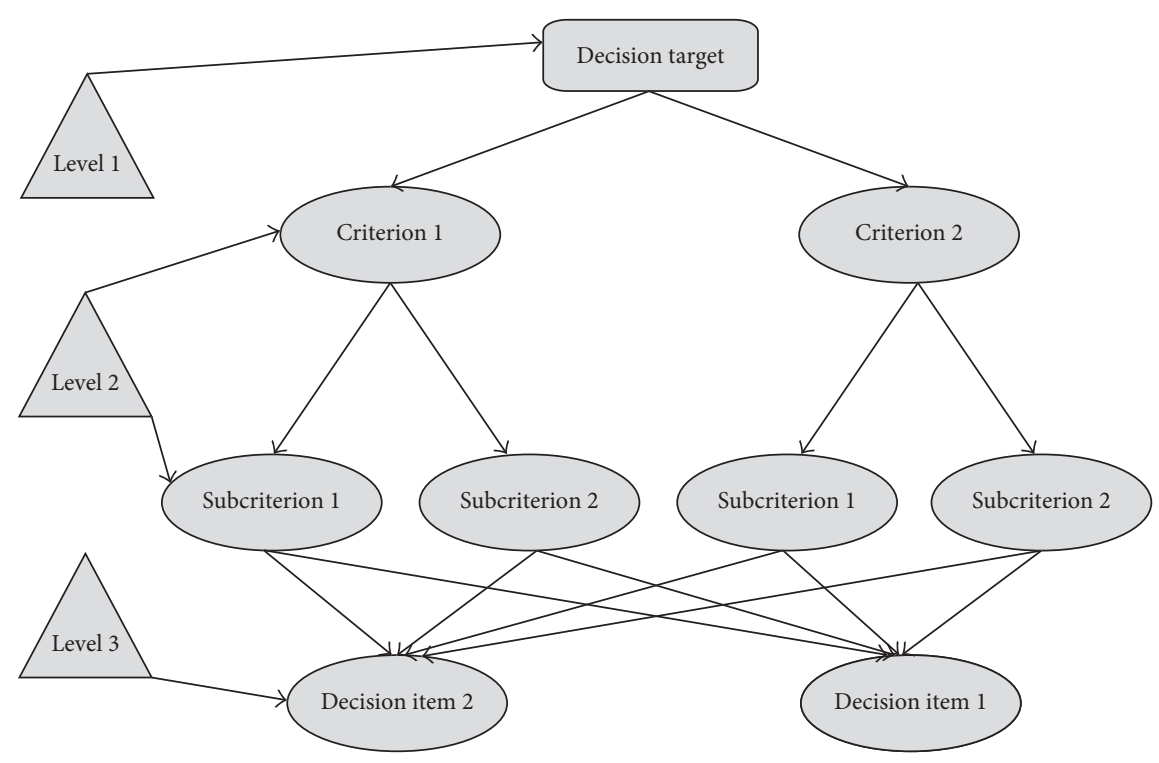

Figure 2: A decision hierarchy illustration.

Measures and programs to reduce the effects of the crisis are usually the following:

(i) Implementation of building regulations

(ii) Setting the laws related to land use

(iii) Implementation of safety rules in tall buildings, hazardous materials control, and so on

(iv) Programs associated to reduce the risks on the products of agriculture

(v) Programs related to the protection of public service of key systems, including protection of power supply and telecommunications systems

(vi) Programs and actions related to the development of network infrastructure, including the construction of freeways away from vulnerable areas

Although governments often require full assistance and support from nongovernmental organizations (NGOs), private and public sectors, and in some cases even international aids, the overall and primary responsibility to deal with the crisis is upon government. The main task of crisis management is to ensure coordination among government agencies and operational resources and, if necessary, nonstate agencies to provide the best anticrisis measures to the best possible potential. NGO resources are sometimes integrated and coordinated in the crisis management system. Management and coordination of tasks related to nongovernment resources is done through the Supreme Council for Risk Management and Central Administration of Crisis Management and operational control group and technical consultancy team which has a representative from nongovernmental organizations in that company (Figure 1).

Reversibility is an indicator of a location and can be defined as an ability to keep itself stable against huge natural disasters without being suffered of devastating harms and
Table 1: Determination of the random index.

\begin{tabular}{ccccccccccc}
\hline$N$ & 1 & 2 & 3 & 4 & 5 & 6 & 7 & 8 & 9 & 10 \\
\hline RI & 0 & 0 & 0.58 & 0.9 & 1.12 & 1.24 & 1.32 & 1.41 & 1.45 & 1.51 \\
\hline
\end{tabular}

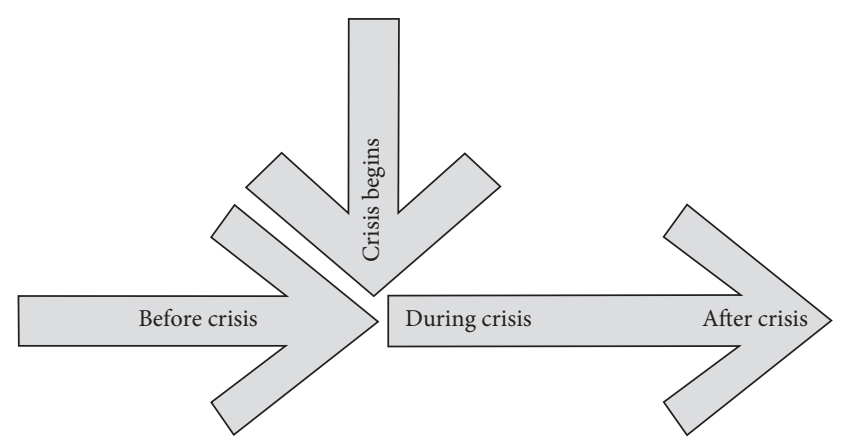

Figure 3: Timing stages of crisis.

losses, reduction of productivity or life quality and being needless of others' aids outside the community [7].

Vulnerability is a term applied to show the scope and amount of damage and losses exerted likely over the communities, buildings, and geographical regions caused by natural disasters. Based on a definition by UNESCO, the environmental sensitivity against the occurrence of a natural disaster is to determine the vulnerability of the environment. The vulnerability can be considered as destruction and lack of outreach and reversibility of the city after the crisis [8].

The most important section of crisis management measures should lead to prevent the occurrences caused by natural disasters to mitigate damages and vulnerabilities. Considering the crisis management in a broader sense than only operation after event occurrence will lead us to reduce dangers, get permanently prepared, and meet necessary needs after occurrence, including emergency and short-term and long-term operations. Since a comprehensive planning 
TABLE 2: Management activities in different stages of crisis management cycle.

\begin{tabular}{|c|c|}
\hline Stage of crisis & Activities and actions \\
\hline Precrisis & $\begin{array}{c}\text { Legislation and following laws } \\
\text { Planning } \\
\text { Approximation and evaluation of earthquake potential } \\
\text { Approximation and estimation of danger } \\
\text { Prevention } \\
\text { Vulnerability determination and decreasing impacts } \\
\text { Being prepared } \\
\text { Raising alarms and warnings } \\
\text { Research and study }\end{array}$ \\
\hline Beginning of crisis & $\begin{array}{c}\text { Announcement and warning } \\
\text { Preliminary evaluation of incident size and dimension } \\
\text { Mobilization } \\
\text { Rescue and search } \\
\text { Rescue and first aid } \\
\text { Activation of crisis management plan } \\
\text { Activation of confronting plan officially } \\
\text { Search, help, and rescue }\end{array}$ \\
\hline During crisis & $\begin{array}{c}\text { Living facilities } \\
\text { Healthcare facilities and observation } \\
\text { Region health condition, injured and survivors } \\
\text { Evacuating people from unsafe regions to safe zones } \\
\text { Exact evaluation of crisis } \\
\text { Announcement }\end{array}$ \\
\hline Postcrisis & $\begin{array}{c}\text { Retrofitting and reestablishing emergency services } \\
\text { Reconstruction } \\
\text { Create temporary shelter } \\
\text { Demolition of unsafe places and cleanup damaged places } \\
\text { Healthcare } \\
\text { Establishment of normal status } \\
\text { Social support } \\
\text { Evaluating and reviewing rules and regulations and crisis management plans } \\
\text { Development } \\
\text { Research and study }\end{array}$ \\
\hline
\end{tabular}

TABLE 3: Major earthquakes in Qazvin.

\begin{tabular}{|c|c|c|}
\hline Earthquake year (A.D.) & Magnitude of earthquake according to Richter scale & Level of damage \\
\hline 864 & 5.2 & Happened in Rey and sensed strongly in Qazvin \\
\hline 958 & 7.7 & $\begin{array}{l}\text { Happened in Taleghan and sensed up to almost } \\
400 \mathrm{~km} \text { from the zero point of the earthquake }\end{array}$ \\
\hline 1119 & 6.5 & $\begin{array}{c}\text { Happened in Qazvin city, killed many and caused } \\
\text { great destruction }\end{array}$ \\
\hline 1226 & 7.2 & $\begin{array}{l}\text { Happened in the region between Ray to Qazvin, } \\
\text { destroyed this region and killed many souls }\end{array}$ \\
\hline 1608 & 7.6 & Destroyed the area of Alamoot and Taleghan \\
\hline 1808 & 5.9 & $\begin{array}{l}\text { Destroyed the whole west arena of Mazandaran and } \\
\text { Taleghan and also some buildings in Qazvin city }\end{array}$ \\
\hline 1901 & 5.4 & Happened in Qazvin region \\
\hline 1962 & 7.2 & $\begin{array}{c}\text { Destroyed the Boein-Zahra region in the south-side } \\
\text { of Qazvin }\end{array}$ \\
\hline 1990 & 7.7 & $\begin{array}{c}\text { It shook a vast area in the west part of Alborz and } \\
\text { caused full destruction of Roodbar, Manjil, Loshan, } \\
\text { and about } 300 \text { villages }\end{array}$ \\
\hline
\end{tabular}

for a city needs enough time and ample costs, then it is required to clarify the vulnerability rate and priority in the planning and actions in the suburban exoccurrence [6].
2.1. Effective Aspects of Vulnerability in Earthquake. The effective aspects of a city against earthquakes can be divided into three general sections [9]: 
TABLe 4: Vulnerability subcriteria data.

\begin{tabular}{|c|c|c|}
\hline Criteria & Minimum & Maximum \\
\hline Population density in the region (people $/ \mathrm{km}^{2}$ ) & 16.99431 (region 17) & 264.0121 (region 12$)$ \\
\hline Immigrants settled in the area (people/region) & 94 (region 1 ) & $10,285$ (region 19$)$ \\
\hline Illiterate population in the region (people/region) & 117 (region 17 ) & 4,852 (region 12 ) \\
\hline Vulnerable populations in the region (people/region) & 311 (region 17 ) & 11,335 (region 19 ) \\
\hline Reverse of sex ratio (man/woman) & 0.113992 (region 17 ) & 1.126783 (region 10$)$ \\
\hline $\begin{array}{l}\text { Sidewalk length with less than } 6 \text { meters in width in } \\
\text { the region ( } \mathrm{m} / \text { region) }\end{array}$ & 236.89 (region 17) & $52,280.51$ (region 2$)$ \\
\hline $\begin{array}{l}\text { Area of old and repairable buildings in the region } \\
\left(\mathrm{km}^{2} / \text { region }\right)\end{array}$ & 0.7166 (region 19) & 54.93 (region 2) \\
\hline $\begin{array}{l}\text { Building segments less than } 200 \text { square meters in the } \\
\text { region (number of buildings/region) }\end{array}$ & 135 (region 11$)$ & 4,156 (region 12 ) \\
\hline $\begin{array}{l}\text { Average number of units in the building of the region } \\
\text { (number of units/building) }\end{array}$ & $1.18($ region 14$)$ & $4.2($ region 19$)$ \\
\hline $\begin{array}{l}\text { Reverse number area of open spaces with an area over } \\
500 \text { square meters in the region }\left(\mathrm{m}^{2} \text { of plot } / \mathrm{km}^{2} \text { of }\right. \\
\text { region) }\end{array}$ & 0.0000007 (region 19) & 0.0000502 (region 4) \\
\hline Especial land uses area in the region $\left(\mathrm{m}^{2} /\right.$ region $)$ & 133.66 (region 4 ) & $164,679.41$ (region 9) \\
\hline Organic texture surface of the region $\left(\mathrm{m}^{2} /\right.$ region $)$ & $\begin{array}{l}\text { Without organic texture region (regions } 9,11,13,15 \text {, } \\
\qquad 16,19)\end{array}$ & $1,307,842.55$ (region 18$)$ \\
\hline $\begin{array}{l}\text { The average number of floors (number of } \\
\text { floors/number of buildings) }\end{array}$ & $1.18($ region 14$)$ & 2.86 (region 19) \\
\hline $\begin{array}{l}\text { Reverse number of access to relief services in the } \\
\text { region }\end{array}$ & Without service (regions $1,2,5,14$ ) & 0.02359 (region 13$)$ \\
\hline $\begin{array}{l}\text { Area of major activity centers in the region } \\
\left(\mathrm{m}^{2} / \text { region }\right)\end{array}$ & 821.87 (region 17) & $1,891,177.54$ (region 14$)$ \\
\hline Employment rate in the region (people $/ \mathrm{km}^{2}$ ) & 525 (region 18$)$ & $7,328$ (region 4$)$ \\
\hline Average area slope (\%/region) & 0.52 (region 16$)$ & 2.3 (region 18 ) \\
\hline Reverse number distance to faults from the region & 0.0000727 (region 8) & 0.0001580 (region 19) \\
\hline $\begin{array}{l}\text { Reverse number average distance to industrial, } \\
\text { chemical, nuclear areas }\end{array}$ & 0.00009 (region 7) & 0.00033 (region 9) \\
\hline $\begin{array}{l}\text { Reverse number region distance to the river and } \\
\text { watercourse }\end{array}$ & 0.000772368 (region 9) & 0.015994882 (region 12) \\
\hline
\end{tabular}

(i) Physical aspects and physical strength of the site

(ii) Site responsiveness to the possibility of outreach after the crisis

(iii) Possible reversibility of city after the crisis

Every city contains several elements that are organized through integrated planning and urban design. It can be said in general that some vulnerability criteria of a city are related to its natural bed specifications, and some are related to the artificial factors. Previous studies confirm that the fault lines, soil quality, and its impact on liquefaction, slope of the region, and existence of streams and rivers in the area have a considerable impact on the amount of damage caused by the earthquake in a city [10]. Perhaps, the physical dimensions can also be perceived as a tangible dimension to the role of urban planning and urbanization in reducing earthquake effects. Physical dimensions can be categorized under the following groups:

(i) City structure and site

(ii) Urban land use (iii) Facilities and infrastructures of the city

Demographic-social texture of the city has a direct relation with the crisis vulnerability. The less the population density in a city region and the balance distribution of density throughout the city, the less the vulnerability against natural disasters.

The city communication network has a very critical role in vulnerability of a city. If a network has not exerted any major losses and then it survives, it is possible to do outreach operations and population transfer to the safe regions quickly. The most important items to be paid more attention about communication network and access in a city are as follows [6]:

(i) Access hierarchy

(ii) Width, length and slope of crossings and their height fitness with walls

(iii) Number of intersections and distance between them

(iv) Location of airport, stations, railway, subway lines, and so on 


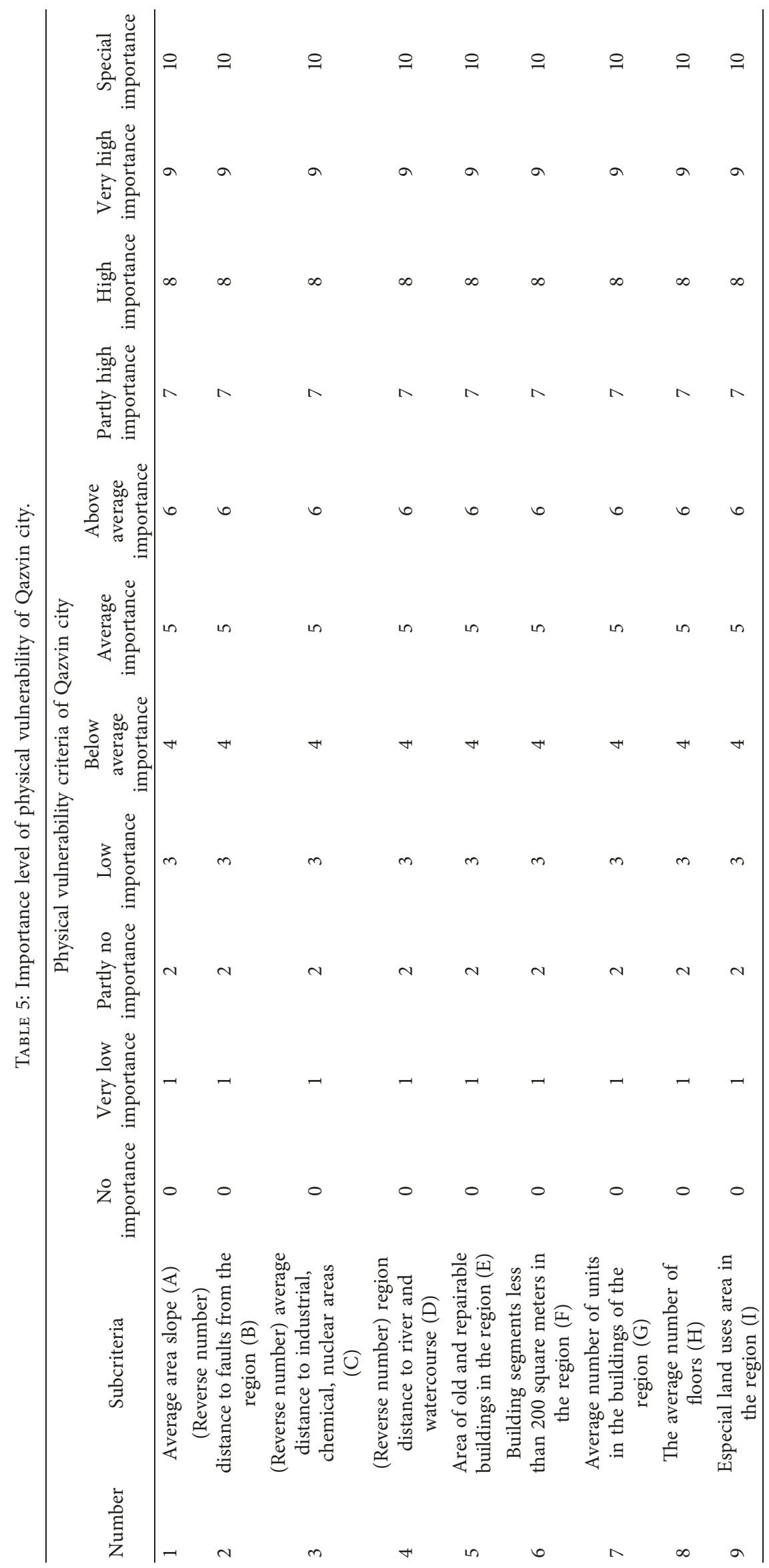




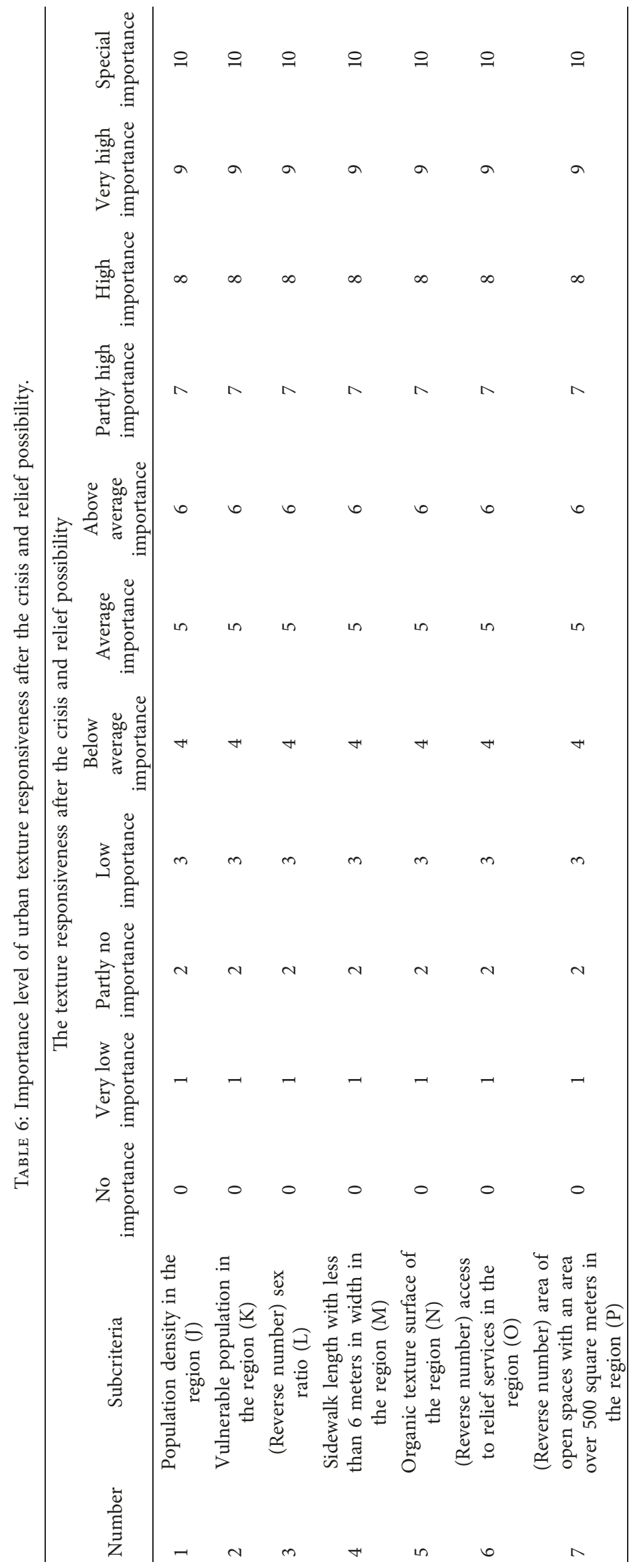




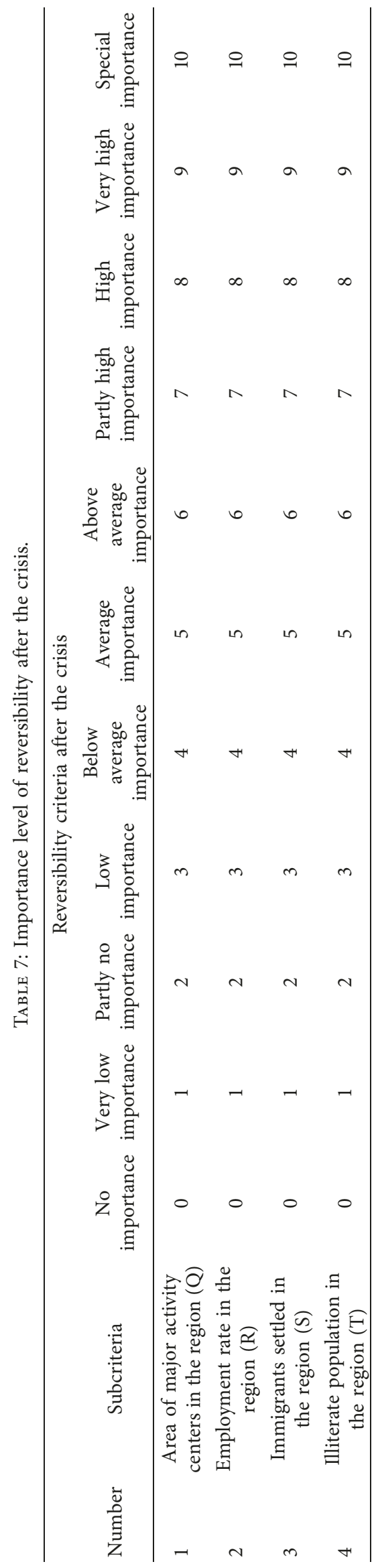






FIGURE 4: Analytic hierarchy process in earthquake disaster management.

Regarding city reversibility, economic and social factors must be considered. It is necessary to carry out next preventive measures; economic centers should be identified in high-risk areas before the accident. In this section, careers at risk have been identified, and prevention programs can be developed to reduce the impact of disasters on the economy of families living in those areas [11]. On the other hand, more urban residents' participation and social involvement will result in better ability for a city to return to normal situation after a crisis. Moreover, resident immigrants and literacy rates are important issues that need to be examined in this context [11].

Inevitably, inhabitants of a city are the most important means of a community which should always be considered as the highest priority and focused more than any other thing. However, there is a direct relation between saving the lives of the people and city infrastructure. If access roads, rails, stations, and such infrastructure are damaged and not accessible after the earthquake, people cannot be safely saved, and thus, the catastrophe will be magnified. Therefore, major infrastructure of a city must be strictly controlled and surveyed to be in service after a natural disaster to provide service for the people and the aid providers.

\section{Analytic Hierarchy Process (AHP)}

Analytic Hierarchy Process (AHP) is one of the most versatile decision-making techniques which reflect the natural behavior and human thought. This technique is the study of complex problems based on their mutual effects and converts them to a simple form and solves them. AHP can be used when faced with competing multiple choice or multicriteria decision-making problems. The criteria can be considered quantitatively and qualitatively. This decisionmaking method is based on latent paired comparisons. The 
TABLE 8: Preference intensity evaluation by binary comparison relatively between criterions in AHP [16].

\begin{tabular}{|c|c|c|}
\hline Preference intensity & Comparison status of “ $i$ " relative to “ $j$ ” & Description \\
\hline (1) & Equally preferred & $\begin{array}{c}\text { Item " } i \text { " has equal priority with " } j \text { ” or there is no } \\
\text { preference }\end{array}$ \\
\hline (3) & Moderately preferred & Item " $i$ " is slightly more important than " $j$ " \\
\hline (5) & Strongly preferred & Item " $i$ " is important than " $j "$ \\
\hline (7) & Very strongly preferred & Item " $i$ " is more important than " $j$ " \\
\hline (9) & Extremely preferred & $\begin{array}{l}\text { Item " } i \text { " is absolutely more important than " } j \text { " and is } \\
\text { not comparable to " } j \text { " }\end{array}$ \\
\hline$(10)$ & Especial importance & $\begin{array}{c}\text { Item " } i \text { " is absolutely more important than " } j \text { " and has } \\
\text { very special importance }\end{array}$ \\
\hline (2), (4), (6), and (8) & Median preference & $\begin{array}{l}\text { Show the median values over preferred values. For } \\
\text { example, } 8 \text { expresses greater importance over } 7 \text { and } \\
\text { less than } 9 \text { for " } i \text { " in comparison to " } j \text { " }\end{array}$ \\
\hline
\end{tabular}

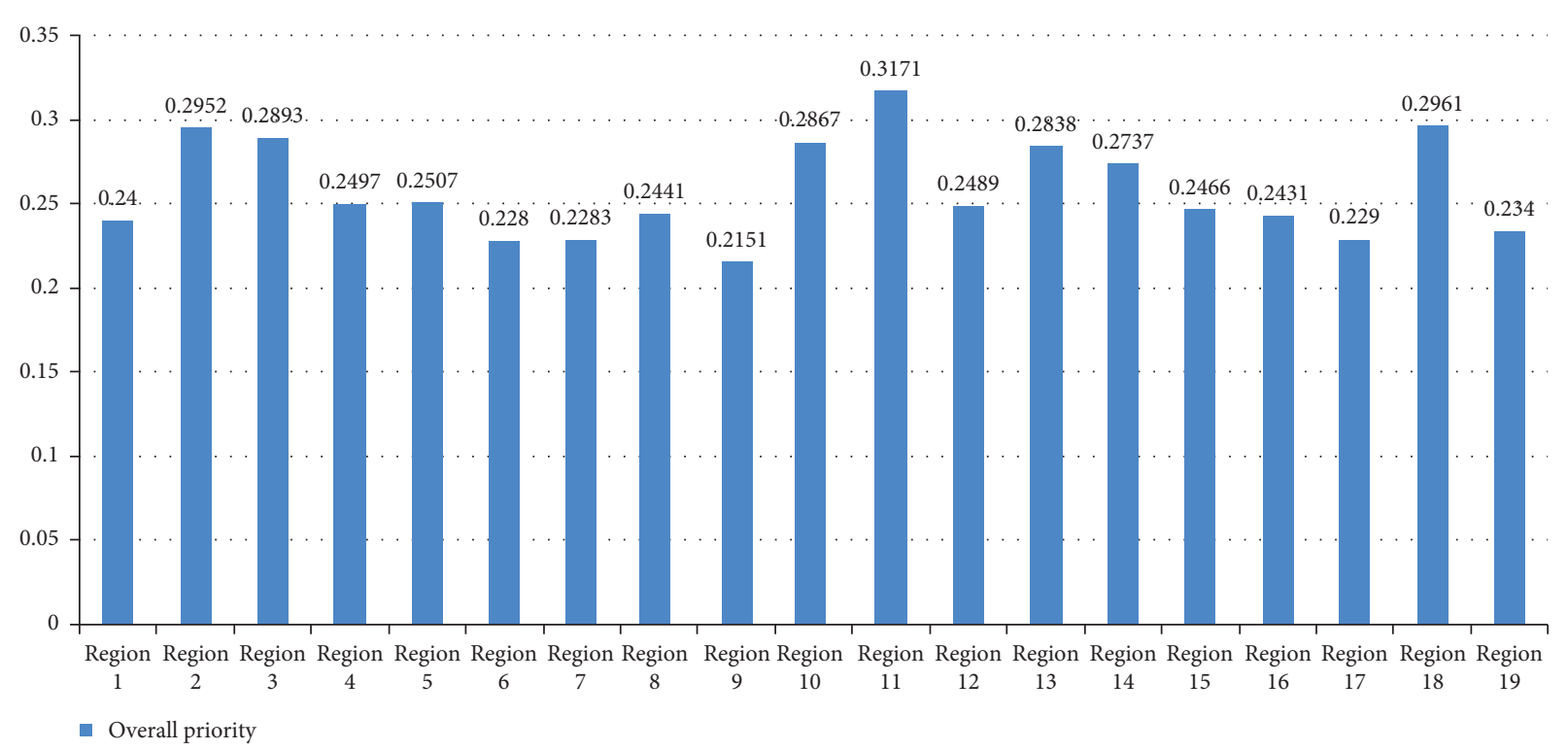

FIGURE 5: Overall priority of each of 19 districts of Qazvin city for physical vulnerability of the city.

TABLE 9: Binary matrix and local priority coefficient of criteria.

\begin{tabular}{lccccc}
\hline Criterion & $\begin{array}{c}\text { Criterion } \\
\text { Management } \\
\text { and decision (D) }\end{array}$ & $\begin{array}{c}\text { Implementation and } \\
\text { operation (E) }\end{array}$ & $\begin{array}{c}\text { Monitoring (F) } \\
\text { Support (G) }\end{array}$ & $\begin{array}{c}\text { Importance coefficient } \\
\text { of criteria }\end{array}$ \\
\hline Management and decision (D) & 1.00 & 3.00 & 5.00 & 7.00 & 0.59337 \\
Implementation and operation (E) & 0.33 & 1.00 & 3.00 & 5.00 & 0.22732 \\
Monitoring (F) & 0.20 & 0.33 & 1.00 & 3.00 & 0.11128 \\
Support (G) & 0.14 & 0.20 & 0.33 & 1.00 & 0.06803 \\
\hline
\end{tabular}

decision maker begins providing a hierarchical tree. The decision hierarchical tree shows the comparable factors and evaluates the competing alternatives in a decision, and then a series of paired comparisons are carried out. The comparisons show the weight of each factor toward competing alternatives to evaluate in a decision. Finally, the hierarchical analysis process logic integrates matrices of pairwise comparisons together in a way to make a better decision.
Principles of AHP are based on definition by Saaty [12] as the following steps:

(i) Define the problem and determine the kind of knowledge sought.

(ii) Structure the decision hierarchy from the top with the goal of the decision, then the objectives from a broad perspective, through the intermediate levels (criteria 
TABLE 10: Local priority coefficient of subcriteria.

\begin{tabular}{|c|c|c|c|}
\hline Subcriteria & Local priority & Subcriteria & Local priority \\
\hline Planning and developing framework $(\mathrm{H})$ & 0.0836 & Establish a united command (I) & 0.4042 \\
\hline Determine a head for each activity $(\mathrm{J})$ & 0.3745 & Determine credit and resource allocation $(\mathrm{K})$ & 0.1378 \\
\hline Use of human resource $(\mathrm{L})$ & 0.1162 & Use of equipment $(\mathrm{M})$ & 0.2323 \\
\hline Increase coverage $(\mathrm{N})$ & 0.6514 & Monitoring costs $(\mathrm{O})$ & 0.2952 \\
\hline Monitoring human resource and equipment $(\mathrm{P})$ & 0.1555 & Quality assurance (Q) & 0.5492 \\
\hline Enhancing coordination (R) & 0.7460 & Safety promotion (S) & 0.1561 \\
\hline $\begin{array}{l}\text { Being equipped with suitable facilities and } \\
\text { appropriate distribution among various sections }(\mathrm{T})\end{array}$ & 0.0979 & - & - \\
\hline
\end{tabular}

TABLE 11: Overall priority coefficient of alternatives based on each subset.

\begin{tabular}{lcccccccccccccc}
\hline & $\mathrm{H}$ & $\mathrm{I}$ & $\mathrm{J}$ & $\mathrm{K}$ & $\mathrm{L}$ & $\mathrm{M}$ & $\mathrm{N}$ & $\mathrm{O}$ & $\mathrm{P}$ & $\mathrm{Q}$ & $\mathrm{R}$ & $\mathrm{S}$ & $\mathrm{T}$ \\
\hline Precrisis (A) & 0.7622 & 0.2323 & 0.5420 & 0.6514 & 0.2323 & 0.1162 & 0.0909 & 0.7523 & 0.2323 & 0.4286 & 0.2000 & 0.4286 & 0.2000 \\
During crisis (B) & 0.0813 & 0.6514 & 0.2601 & 0.1162 & 0.6514 & 0.6514 & 0.4545 & 0.0833 & 0.6514 & 0.1429 & 0.6000 & 0.1429 & 0.6000 \\
Postcrisis (C) & 0.1565 & 0.1162 & 0.1979 & 0.2323 & 0.1162 & 0.2323 & 0.4545 & 0.1644 & 0.1162 & 0.4286 & 0.2000 & 0.4286 & 0.2000 \\
\hline
\end{tabular}

on which subsequent elements depend) to the lowest level (which usually is a set of the alternatives).

(iii) Construct a set of pairwise comparison matrices. Each element in an upper level is used to compare the elements in the level immediately below with respect to it.

(iv) Use the priorities obtained from the comparisons to weigh the priorities in the level immediately below. Do this for every element. Then for each element in the level below, add its weighed values and obtain its overall or global priority. Continue this process of weighing and adding until the final priorities of the alternatives in the bottom most level are obtained.

3.1. AHP Model for Earthquake Crisis Management. Application of AHP to earthquake crisis management requires the following procedure.

3.1.1. Modeling. AHP requires to break a problem via multiple levels in the hierarchy of levels. Design elements include "decision criteria" and "decision alternative." The high level indicates the main goal of decision-making process. The second is to represent the major fundamental factors which may be broken down into more detailed subindices in the next level, and the last also offers options for decision [13]. Figure 2 represents a sample hierarchical structure of a decision problem including a four-level hierarchy consisting goals, criteria, subcriteria, and alternatives.

Converting the problem into a hierarchical structure is the most important part of AHP since the process must explain complex problems simply to be consistent with the human mind and nature. Performing comparisons between different alternatives is made based on judgment about the importance of each alternative via paired comparisons. After designing the hierarchy of alternatives, decision maker should be able to measure a series of matrices that evaluate the numerical importance or priority of indexes together, and it provides each alternative compared to others according to the criteria. This trend is done with pairwise comparisons between alternatives (binary comparison) and assigning numerical scores which indicate the priority or importance among the alternatives [14].

Determination of decision alternative weights via set of numerical calculations is the next step in AHP to determine preference of each alternative using pairwise comparison matrices. In other words, the relative weight of each element should be multiplied by high-weight elements to get the final weight to rank the alternatives. By doing this step for each alternative, the final score will be calculated according to the following equation [14]:

$$
\text { pr. }=\sum_{k=1}^{n} \sum_{i=1}^{m} W_{k} W_{i}\left(g_{i j}\right),
$$

where $W_{k}$ is a preference coefficient of the criterion $W_{i}, k$ is the preference coefficient of subcriterion $i$, and $g_{i j}$ is criterion score related to subcriterion $i$.

Nearly all calculations in AHP are performed based on the primary judgment of decision maker in the form of pairwise comparison matrices, and it removes all incompatibilities and errors in the comparison and determination of the importance between options and indices of final results obtained from calculations.

Inconsistency rate (IR) is a measure that determines the consistency of the results and how priorities made by comparisons can be trusted. Perhaps, the comparison of two alternatives is simple, but when the number of alternatives increases, the consistency could not be trustable, and trust must be achieved using inconsistency rate. Inconsistency rate is generally computed through the following steps: 





TABLE 13: Overall priority of each of 19 districts of Qazvin city for physical vulnerability of the city.

\begin{tabular}{|c|c|c|c|c|c|c|c|c|c|c|}
\hline \multirow{2}{*}{ Region } & \multicolumn{10}{|c|}{ Subcriteria } \\
\hline & A & $\mathrm{B}$ & $\mathrm{C}$ & $\mathrm{D}$ & $\mathrm{E}$ & $\mathrm{F}$ & G & $\mathrm{H}$ & I & Total \\
\hline 1 & 0.028 & 0.022 & 0.038 & 0.033 & 0.06 & 0.004 & 0.041 & 0.0019 & 0.0121 & 0.240 \\
\hline 2 & 0.0046 & 0.012 & 0.001 & 0.0136 & 0.033 & 0.033 & 0.058 & 0.09 & 0.05 & 0.295 \\
\hline 3 & 0.0091 & 0.0078 & 0.0064 & 0.001 & 0.066 & 0.033 & 0.012 & 0.098 & 0.056 & 0.2893 \\
\hline 4 & 0.035 & 0.016 & 0.086 & 0.007 & 0.064 & 0.033 & 0.001 & 0.007 & 0.00069 & 0.249 \\
\hline 5 & 0.0014 & 0.036 & 0.0089 & 0.0028 & 0.0077 & 0.087 & 0.0009 & 0.007 & 0.099 & 0.2507 \\
\hline 6 & 0.003 & 0.0098 & 0.0086 & 0.064 & 0.00078 & 0.0051 & 0.043 & 0.0047 & 0.089 & 0.227 \\
\hline 7 & 0.036 & 0.079 & 0.045 & 0.0013 & 0.038 & 0.0057 & 0.0014 & 0.0146 & 0.0073 & 0.228 \\
\hline 8 & 0.0037 & 0.098 & 0.0075 & 0.0065 & 0.035 & 0.0026 & 0.022 & 0.068 & 0.0008 & 0.244 \\
\hline 9 & 0.0014 & 0.0086 & 0.056 & 0.0014 & 0.043 & 0.058 & 0.005 & 0.033 & 0.0087 & 0.215 \\
\hline 10 & 0.086 & 0.084 & 0.033 & 0.0063 & 0.0014 & 0.0056 & 0.035 & 0.0064 & 0.029 & 0.2867 \\
\hline 11 & 0.0064 & 0.09 & 0.087 & 0.0043 & 0.017 & 0.0034 & 0.056 & 0.015 & 0.038 & 0.317 \\
\hline 12 & 0.008 & 0.033 & 0.077 & 0.012 & 0.0054 & 0.0075 & 0.064 & 0.021 & 0.021 & 0.248 \\
\hline 13 & 0.07 & 0.0086 & 0.099 & 0.075 & 0.0063 & 0.0097 & 0.01 & 0.0012 & 0.004 & 0.283 \\
\hline 14 & 0.0210 & 0.036 & 0.0056 & 0.0086 & 0.0087 & 0.0098 & 0.046 & 0.041 & 0.097 & 0.273 \\
\hline 15 & 0.002 & 0.0045 & 0.0076 & 0.014 & 0.026 & 0.086 & 0.09 & 0.0089 & 0.0076 & 0.246 \\
\hline 16 & 0.0089 & 0.021 & 0.012 & 0.033 & 0.065 & 0.0052 & 0.0053 & 0.0067 & 0.086 & 0.243 \\
\hline 17 & 0.021 & 0.065 & 0.063 & 0.0064 & 0.0051 & 0.053 & 0.0013 & 0.0056 & 0.0086 & 0.229 \\
\hline 18 & 0.027 & 0.027 & 0.0056 & 0.0089 & 0.099 & 0.093 & 0.0083 & 0.026 & 0.0013 & 0.296 \\
\hline 19 & 0.0044 & 0.0048 & 0.036 & 0.0089 & 0.023 & 0.098 & 0.0031 & 0.046 & 0.01 & 0.234 \\
\hline
\end{tabular}

TABLE 14: Overall priority of each of 19 districts of Qazvin city for the texture responsiveness criteria after the crisis and relief possibility.

\begin{tabular}{|c|c|c|c|c|c|c|c|c|}
\hline \multirow{2}{*}{ Region } & \multicolumn{8}{|c|}{ Subcriteria } \\
\hline & $\mathrm{J}$ & $\mathrm{K}$ & $\mathrm{L}$ & M & $\mathrm{N}$ & $\mathrm{O}$ & $\mathrm{P}$ & Total \\
\hline 1 & 0.0012 & 0.0023 & 0.0014 & 0.0123 & 0.0057 & 0.095 & 0.0021 & 0.12 \\
\hline 2 & 0.05 & 0.00124 & 0.066 & 0.031 & 0.0058 & 0.0013 & 0.0041 & 0.159 \\
\hline 3 & 0.002 & 0.0033 & 0.013 & 0.051 & 0.044 & 0.0036 & 0.0012 & 0.118 \\
\hline 4 & 0.032 & 0.032 & 0.0013 & 0.0045 & 0.065 & 0.0034 & 0.0018 & 0.14 \\
\hline 5 & 0.007 & 0.0059 & 0.089 & 0.013 & 0.0026 & 0.0033 & 0.0028 & 0.123 \\
\hline 6 & 0.056 & 0.021 & 0.0031 & 0.0035 & 0.0031 & 0.0085 & 0.04 & 0.135 \\
\hline 7 & 0.0012 & 0.055 & 0.0032 & 0.063 & 0.0088 & 0.0098 & 0.001 & 0.142 \\
\hline 8 & 0.0026 & 0.0263 & 0.012 & 0.012 & 0.0044 & 0.0066 & 0.051 & 0.114 \\
\hline 9 & 0.036 & 0.087 & 0.0021 & 0.0021 & 0.0065 & 0.0061 & 0.0028 & 0.142 \\
\hline 10 & 0.041 & 0.0074 & 0.0086 & 0.0098 & 0.0062 & 0.0038 & 0.049 & 0.1258 \\
\hline 11 & 0.015 & 0.0061 & 0.0036 & 0.091 & 0.013 & 0.0066 & 0.0011 & 0.136 \\
\hline 12 & 0.028 & 0.036 & 0.021 & 0.0028 & 0.0011 & 0.022 & 0.0034 & 0.114 \\
\hline 13 & 0.061 & 0.0056 & 0.0022 & 0.0033 & 0.069 & 0.0031 & 0.0046 & 0.148 \\
\hline 14 & 0.0066 & 0.0037 & 0.0011 & 0.0036 & 0.0045 & 0.011 & 0.098 & 0.128 \\
\hline 15 & 0.031 & 0.021 & 0.053 & 0.0066 & 0.0012 & 0.0041 & 0.0031 & 0.12 \\
\hline 16 & 0.044 & 0.0031 & 0.031 & 0.0069 & 0.0089 & 0.0099 & 0.0079 & 0.111 \\
\hline 17 & 0.007 & 0.0065 & 0.0056 & 0.0044 & 0.0031 & 0.078 & 0.01 & 0.114 \\
\hline 18 & 0.021 & 0.0212 & 0.0063 & 0.0036 & 0.0491 & 0.0013 & 0.00234 & 0.104 \\
\hline 19 & 0.017 & 0.0036 & 0.0036 & 0.063 & 0.0031 & 0.0028 & 0.043 & 0.136 \\
\hline
\end{tabular}

Step 1: calculating the weighted sum vector: matrix is multiplied the pairwise comparisons by the column vector "local priority," and a new vector obtained in this way is called the Weighted Sum Vector (WSV).
Step 2: calculating the inconsistency vector: the elements of weighted sum vector are divided by relative priority vector and the result is Inconsistency Vector (IV).

Step 3: obtaining $\lambda_{\text {max }}$ : mean of inconsistency vector elements gives the value of $\lambda_{\max }$. 
Step 4: calculating the inconsistency index: inconsistency index is defined by (2) where $n$ is the number of alternatives in the problem:

$$
\mathrm{CI}=\frac{\lambda_{\max }-n}{n-1}
$$

Step 5: calculation of inconsistency ratio or incompatibility test: a mechanism which has been determined to consider the consistency in the analysis is calculating inconsistency ratio (CR) obtained from inconsistency index divided by random index by (3). If this ratio is less than or equal to 0.1 , the consistency is accepted in judgments; otherwise, it should be reconsidered in judgment [13]. Random index values are derived from Table 1.

$$
\mathrm{CR}=\frac{\mathrm{CI}}{\mathrm{RI}}
$$

\section{Crisis Management Methodology and Vulnerability Assessment Model}

Crisis management in this study was considered in three stages: precrisis, during crisis, and postcrisis. The vulnerability assessment in the precrisis stage must identify the failures and prioritize the planning and resource allocation. The important issue is the fundamental difference between the two concepts of risk probability and vulnerability against the natural hazards. In fact, vulnerability is beyond taking a risk or hazard zonation and comes from the synthesis of various information layers. Vulnerability can be considered the sum of three factors: physical strength of site, lack of relief possibility, and reversibility of city after crisis.

Vulnerability of 19 urban districts of Qazvin was assessed through AHP considering major criteria. Therefore, a thorough study of the geographical characteristics of Qazvin was performed. Then the most important criteria were identified and classified to manage the crisis.

To reach a comprehensive crisis management system, the crisis management cycle must first be exactly identified and then policies for different stages of the planning cycle be made. Various phases of crisis management cycle include preparation, responsibility, outreach, reconstruction, and finally improvement. Each of these steps is divided into different microactivities [15]. In addition, it must be noted that each of the activities relates to a period. Thus, the time stages should be considered for precrisis, onset of the crisis, during the crisis, and after the crisis. The chart of different time steps is shown in Figure 3. In addition, microactivities and actions needed for each step are listed in Table 2.

As shown in Table 2, the precrisis actions are those via which the citizens, officials, and public become aware of the crisis onset during a concise program. They from the perspective of the operational program. During the crisis phase, activities and microactivities are done, hoping to reduce the scope of the crisis to an acceptable level. After the crisis is a long-term process of restoring the situation to normal. After a certain period, the situation is led to the
TABLE 15: Overall priority of each of 19 districts of Qazvin city for the reversibility criteria after the crisis.

\begin{tabular}{lccccc}
\hline \multirow{2}{*}{ Region } & $\mathrm{Q}$ & $\mathrm{R}$ & $\mathrm{S}$ & $\mathrm{T}$ & Total \\
\hline 1 & 0.0036 & 0.0063 & 0.0021 & 0.068 & 0.08 \\
2 & 0.021 & 0.031 & 0.031 & 0.016 & 0.099 \\
3 & 0.0078 & 0.0069 & 0.054 & 0.009 & 0.077 \\
4 & 0.0044 & 0.031 & 0.055 & 0.015 & 0.105 \\
5 & 0.033 & 0.033 & 0.041 & 0.028 & 0.1357 \\
6 & 0.009 & 0.0110 & 0.081 & 0.006 & 0.107 \\
7 & 0.0028 & 0.002 & 0.0011 & 0.0921 & 0.098 \\
8 & 0.031 & 0.011 & 0.024 & 0.011 & 0.077 \\
9 & 0.098 & 0.021 & 0.0089 & 0.01 & 0.138 \\
10 & 0.026 & 0.03 & 0.047 & 0.012 & 0.115 \\
11 & 0.052 & 0.0036 & 0.005 & 0.015 & 0.076 \\
12 & 0.01 & 0.038 & 0.0039 & 0.054 & 0.106 \\
13 & 0.0013 & 0.056 & 0.001 & 0.0077 & 0.066 \\
14 & 0.049 & 0.0021 & 0.01 & 0.0049 & 0.066 \\
15 & 0.0014 & 0.099 & 0.021 & 0.053 & 0.175 \\
16 & 0.03 & 0.033 & 0.045 & 0.023 & 0.131 \\
17 & 0.08 & 0.0021 & 0.02 & 0.0079 & 0.11 \\
18 & 0.025 & 0.035 & 0.052 & 0.077 & 0.189 \\
19 & 0.002 & 0.01 & 0.073 & 0.026 & 0.111 \\
\hline & & & & &
\end{tabular}

initial state, and the cycle is ready to deal with another crisis. Review and evaluation of policies, laws, and management plans are important at this stage of the crisis management process to be able to better control the consequences of future crisis.

Vulnerability analysis of the urban textures in 19 urban districts in Qazvin was considered based on 3 main criteria: physical vulnerability, texture responsiveness after crisis and outreach possibility, and city reversibility after crisis. Total 20 subcriteria were evaluated using AHP.

Physical vulnerability of the Qazvin city was considered under the following subcriteria:

(i) Average area slope

(ii) Distance reverse of faults from the region

(iii) Average distance reverse of industrial, chemical, and nuclear areas

(iv) Distance reverse of region from the river and watercourse

(v) For repair and destruction building area in the region

(vi) Lots less than 200 square meters in the region

(vii) Average number of units in buildings of the region

(viii) Average number of floors

(ix) Especial land uses area in the region

Texture responsiveness after the crisis and relief possibility was considered under the following subcriteria: 


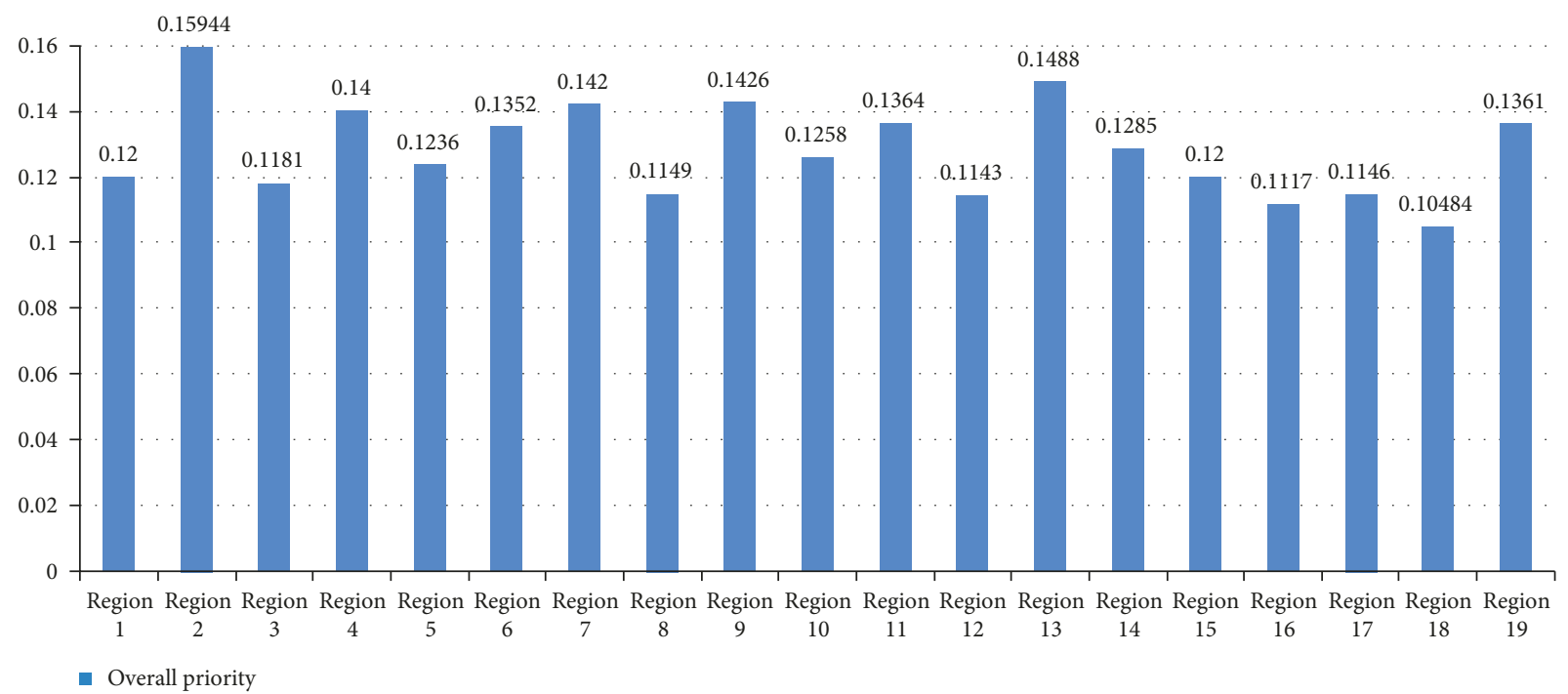

FiguRE 6: Overall priority of each of 19 districts of Qazvin city for the texture responsiveness criteria after the crisis and relief possibility.



FIgURE 7: Overall priority of each of 19 districts of Qazvin city for the reversibility criteria after the crisis.

(i) Population density in the region

(ii) Vulnerable population in the region

(iii) Sex ratio reverse

(iv) Length of crossings with less than 6 meters in width in the region

(v) Organic texture surface of the region

(vi) Reverse access to outreach services in the region

(vii) Reverse area of open spaces with an area over 500 square meters in the region

Reversibility after the crisis was considered under the following subcriteria: (i) Area of major activity centers in the region

(ii) Employment rate in the region

(iii) Immigrants settled in the region

(iv) Illiterate population in the region

\section{Data Collection and Analysis}

General data about Qazvin city including urban texture, socioeconomic factors, population density, and building conditions were collected through a questionnaire survey. Qazvin is recognized as a major city in Iran, according to the criteria and definitions of urban 


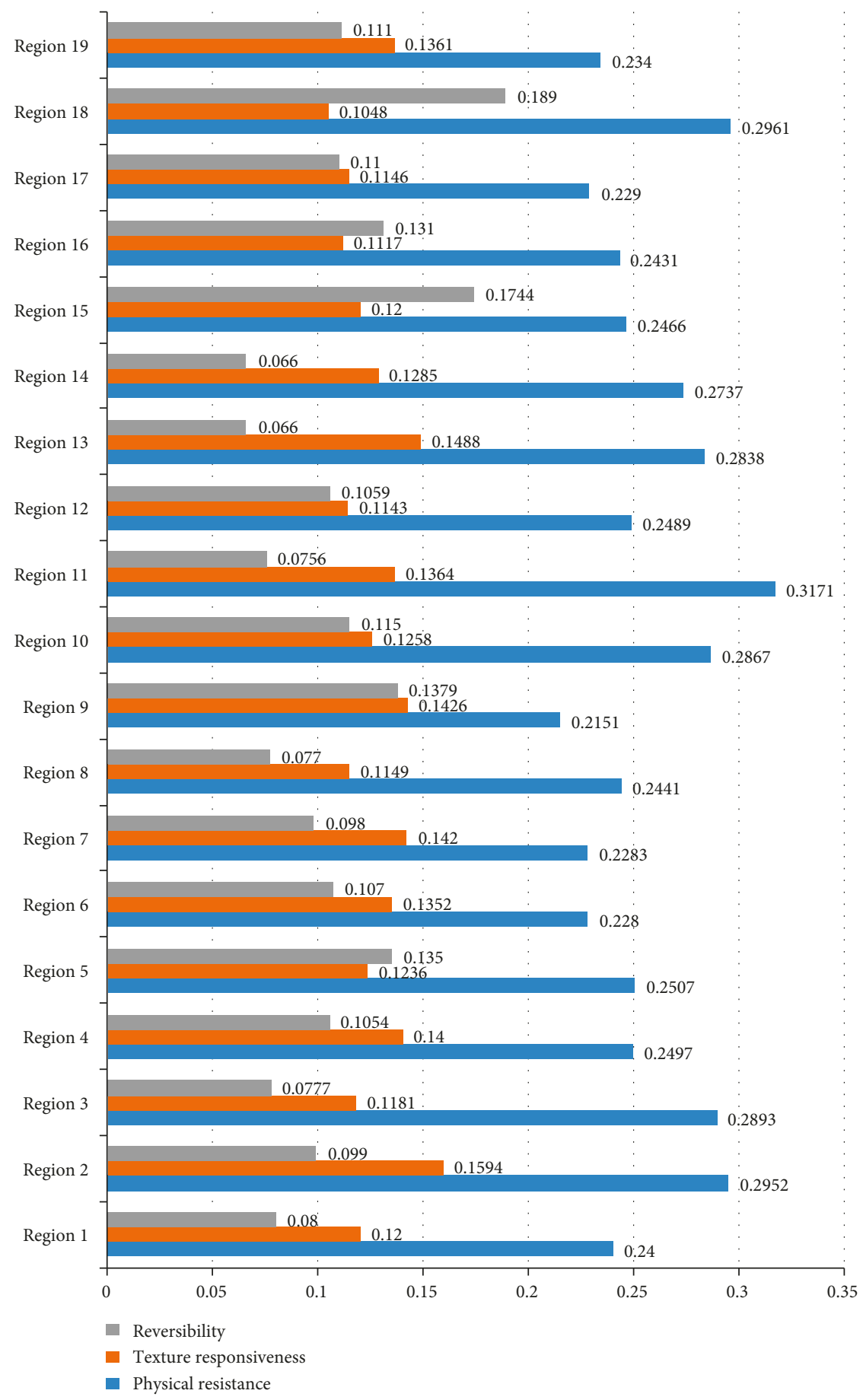

FIGURE 8: Overall priority of 19 districts of Qazvin city for three main vulnerability categories.

planning and sociology. In addition, the city is close to Tehran and it has a political, social, and cultural position. It can be used as a resource area in a national disaster. Its development has caused the emergence of a lot of facilities for the citizens, but its uncontrolled growth has led to some heterogeneous sites in the city, and finally it has transferred various vulnerabilities into the city. On the other hand, this city had many earthquake experiences, and as a historic texture, it can be a model for other states in the region.
The city is too vulnerable against natural disasters such as earthquake due to its geographical situation. Another issue that causes the intensive vulnerability of different regions of the city is the existence of old and uneven sites in the city center which have been built close to each other. The majority of houses are not resistant and do not conform to earthquake standards. Another problem with these sites is limited access, which makes it difficult for the citizens to get the relief aids after the occurrence of an earthquake and can cause a human tragedy in critical conditions. During its 


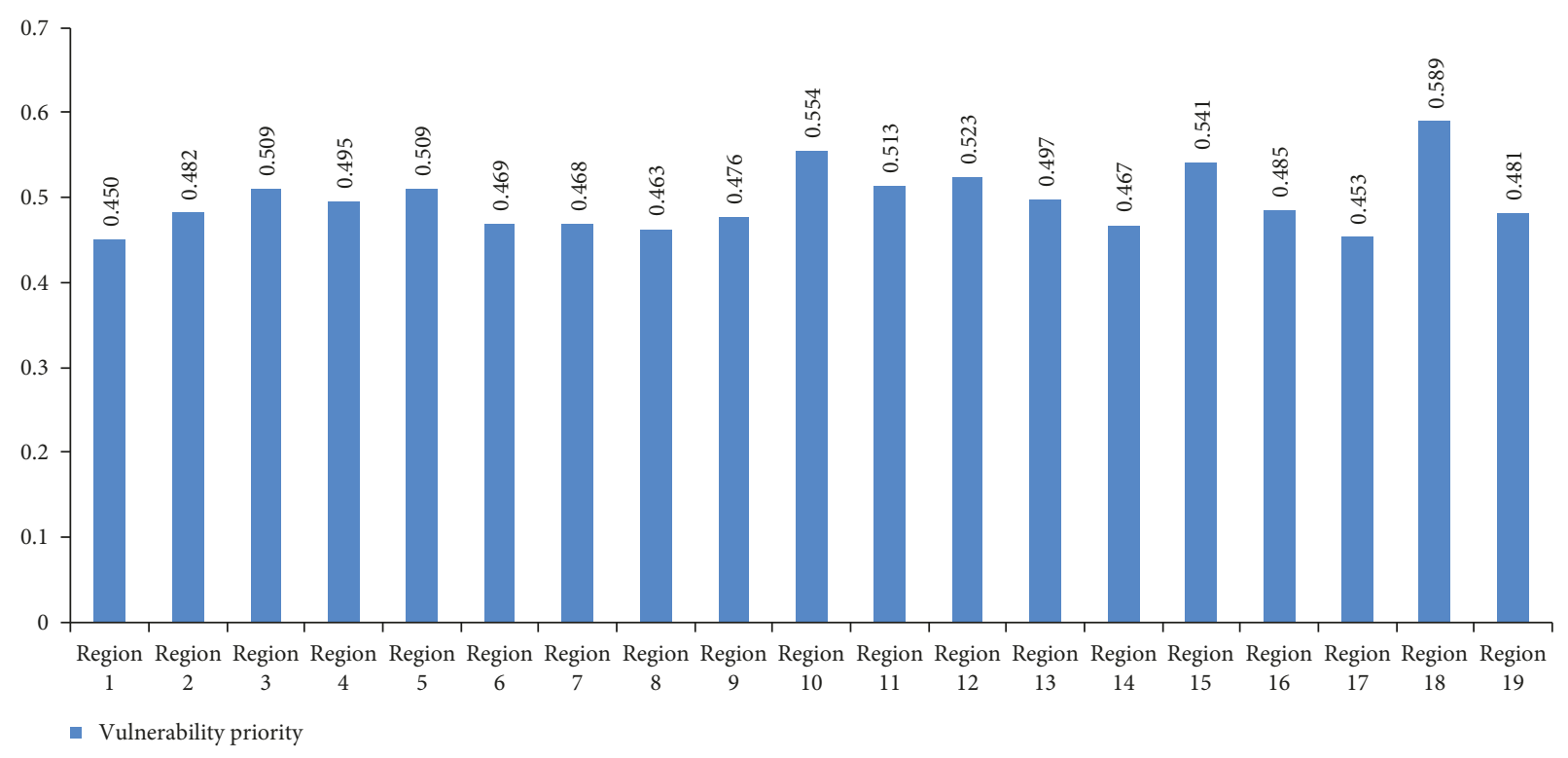

FIgURE 9: Final vulnerability priorities of different regions in Qazvin city.

TABle 16: Vulnerability categories of different regions in Qazvin city.

\begin{tabular}{lc}
\hline Regions & Vulnerability level \\
\hline $1,2,4,6,7,8,9,14,16,17,19$ & Low vulnerability (0.4509-0.496) \\
$3,5,11,12,13,15$ & Moderate vulnerability \\
10,18 & High vulnerability $(0.543-0.589)$ \\
\hline
\end{tabular}

history, Qazvin has experienced several earthquakes with some major ones listed in Table 3.

5.1. Data Collection. Study data were collected through two different sources. Demographic information of Qazvin city such as people, urban construction, and other city properties were categorized under 20 subcriteria and were collected from Tehran Disaster Mitigation and Management Organization (TDMMO) which are derived from Population and Housing Census (2012) statistics, The Master Plan of Qazvin (2010), and Spatial Planning of Qazvin Province (2010). Table 4 includes some major data from this survey.

To apply hierarchical analysis, a binary comparison between criteria is required. A questionnaire was designed and administered among consulting and contractor engineers, project managers, urban facility managers, academicians, and some experts in Qazvin municipality. Then, the level of importance of 20 vulnerability subcriteria was derived. Total 50 questionnaires were distributed from which 35 were returned. The returned questionnaires were fairly from all different regions of the city; 13 respondents were municipality managers, 13 urban facility managers, 6 consultant firms, 6 university lecturers, and 2 project managers. The results obtained from questionnaire survey about three main criteria namely physical vulnerability, urban texture responsiveness after the crisis, and Qazvin city reversibility after the crisis are presented in Tables 5-7, respectively.

5.2. Applying AHP Model for Earthquake Crisis Management. The model was developed in three main steps of crisis including precrisis, during crisis and postcrisis to find out the optimal step for crisis management. On the other hand, the optimal step was selected based on four criteria: "Management and decision making," "Implementation and operation," "Monitoring," and "Support."

Management and decision-making criterion was divided into four subcriteria: "Planning and developing a framework," "Establish a unified command," "Determination of a trustee (leader) for each activity," and "Determination of credits, funding, and resources allocation."

Implementation and operations was classified under three subcriteria: "Use of human resources," "Use of equipment," and "Increased coverage."

Monitoring criterion was divided into three subcriteria: "Monitoring the costs," "Monitoring the Human Resources (HR) and equipment," and "Quality monitoring."

Finally, support criterion was divided into three subcriteria: "Enhancing coordination," "Safety promotion," and "Being equipped with suitable facilities and appropriate distribution among various organs." The hierarchical process diagram is shown in Figure 4.

Comparisons between different alternatives were performed based on judgment on the importance of each alternative via paired comparisons. After designing the hierarchy, the decision maker should be able to measure a series of matrices that evaluate the numerical importance or priority of indexes, and it provides each alternative compared to others according to the criteria. This trend is done with pairwise comparisons between alternatives 




FigURE 10: Hierarchy tree of vulnerability assessment for high-risk regions of Qazvin.

(binary comparison) and assigning numerical scores which indicate the priority or importance among the alternatives [14]. To do this, usually comparison of alternatives is used with indices " $i$ " proportion to options or indices " $j$ " which the valuation of indices as compared together (Table 8) [16].

Pairwise comparisons are recorded in a " $n \times n$ " matrix, and the matrix is called binary comparison of criteria. All elements of this matrix are positive and calculated according to the reverse principle in the analytic hierarchy process. Since determination of importance degree and prioritization of indices is an important issue, and all calculations about AHP are performed based on pairwise comparisons, it is reasonable to determine the importance degree and prioritization of indices according to experts in different urban fields. Therefore, a questionnaire was designed to collect importance of each urban criterion based on engineering experience and using the credible resources.

Pairwise comparison of criteria was performed, and the geometric mean was used since it is more accurate to calculate the criterion index (local priority). To calculate the coefficient of criteria, geometric mean in the rows of matrix 
was first obtained, and then it was normalized. Sum of the coefficients of multiple criteria is equal to 1 , and it is an indication of the local priority of the criteria as can be seen in Table 9.

Local priority (coefficient) of all subcriteria was similarly calculated, as illustrated in Table 10.

Finally, the priority coefficients were calculated based on individual subsets using binary matrices, geometric mean and normalization (Table 11).

5.3. Integration of Local Priorities. The local priority of each element should be multiplied by high-weight elements to get the overall priority to rank the alternatives. Overall priority of each alternative was calculated by (1). The results are listed in Table 12. Final scores of the alternatives show that alternative $\mathrm{B}$ (during crisis) is best choice followed by alternative $\mathrm{A}$ (precrisis) and $\mathrm{C}$ (postcrisis), respectively. AHP calculations were performed based on the primary judgment of decision makers in the form of pairwise comparisons matrices where it removes all incompatibilities and errors in the comparison and determination of the importance and indices.

Local priority and overall priority of all 20 subcriteria were also calculated to assess the vulnerability of the city. Using Microsoft Excel, a $20 \times 20$ matrix was established, and the hierarchical analysis formula was applied. Overall priority of each subcriterion for three different criteria namely "physical vulnerability of the city," "texture responsiveness criteria after the crisis and relief possibility," and "reversibility criteria after the crisis" are presented in Tables 13-15, respectively.

\section{Results and Discussions}

Tables 5-7 simply represent the outcomes of the survey and statistical analysis of the questionnaire results and provide a general view about 20 subcriteria. For example, Table 5 shows that among 9 subcriteria under physical vulnerability of Qazvin city, "Especial land uses area in the region" has the highest importance from the viewpoint of the respondents, where "Building segments less than 200 square meters in the region" has the least importance on the physical vulnerability of Qazvin city. Among the subcriteria related to urban texture responsiveness after the crisis and relief, "Access to relief services in the region" was the most important from the viewpoint of respondents (Table 6). "Area of major activity centers" was the most important subcriteria amongst the others under reversibility of Qazvin city after the crisis (Table 7).

However, AHP results and considering the priority coefficients and pairwise comparisons of the subcriteria under four criteria of "Management and decision making," "Implementation and operation," "Monitoring," and "Support" in three stages of precrisis, during crisis, and postcrisis resulted in Tables 13-15 which are the focal point of the present research study. Considering physical responsiveness ability of the city, region 11 with 0.3171 is the most vulnerable region as shown in Figure 5. Regions 18 and 2 with 0.2961 and 0.2952 are in next ranks, respectively. Regions $2,3,10,11,13$, 14 , and 18 are the most vulnerable regions, while other regions have no major difference. The vulnerability numbers are like normal distribution through the city. It is a good point in city properties, and it means that construction and urban condition are nearly the same through the city, so it makes all plans easy to implement after a crisis.

The second vulnerability assessment category is texture responsiveness of the city. The values are less than 0.16 , where region 2 with 0.1594 has the highest vulnerability in urban texture responsiveness (Figure 6). This category unlike the previous does not have major tolerance in the results where numbers are between "0.104" and "0.159." It means that the city condition in texture responsiveness is almost similar in 19 regions and the relief and aid actions should be distributed moderately throughout the city. Regions 18 and 16 have the best condition after a crisis.

The subcriteria of "area of major activity centers in the region," "employment rate in the region," "immigrants settled in the region," and "illiterate population in the region" were studied under city reversibility and are presented in Figure 7. Regions 18 and 15 with 0.189 and 0.1744 , respectively, have the highest vulnerability in this issue. These two regions moreover have a significant difference with the other regions where region 9 with 0.1379 stands in third place. Regions 13 and 14 have the best position with the same 0.066 . This result reveals that in reversibility plan which should be designed by municipality, an exact attention must be paid to its construction process. Major tolerance in vulnerability reveals that there is a major problem after crisis in social condition, relief, and reconstruction.

Vulnerability numbers for all three categories, city physical vulnerability, responsiveness of urban texture and relief possibility after the crisis, and city reversibility criterion after the crisis are presented in Figure 8 for better comparison of the results.

It can be concluded from the results that region 11 for the category of city physical vulnerability, region 2 for the responsiveness of urban texture after the crisis and relief possibility, and region 18 for city reversibility should be focused more for mitigation planning during and after a crisis.

Final vulnerability priorities for each region of Qazvin city are shown individually in Figure 9 based on AHP calculations. Totally, vulnerability assessment based on three main categories and criteria of vulnerability, and 20 subcriteria reveals that regions 18 and 10 have high vulnerability risk. Regions 15, 12, 11, 5, 3, and 13 stand in next ranks, respectively.

Based on overall priority values, regions have been further categorized into 3 levels of vulnerability risk (Table 16). These categories are low vulnerability (less than 0.496$)$, moderate vulnerability (0.496 to 0.543$)$, and high vulnerability (more than 0.543 ) to specify level of risk in each region.

The vulnerability tree presented in Figure 10 differently shows the vulnerability priority by each subcriterion. This can be a key outcome of the analysis and study. It schematically shows three main categories and 20 subcriteria. Vulnerability numbers under each subcriteria for the highrisk regions indicate that municipality should focus on which region to improve the city mitigation elements. 
According to Figure 10, high population density, area of old and repairable buildings, shortage access to relief and medical services, immigrants settled, a few organic texture area, and sidewalks with less than 6 meters width in the region are the most important elements affecting the vulnerability of these regions.

\section{Conclusions}

Assessment of the vulnerability and immunization should be done in zonation and urban texture scale in order to reduce the effects of earthquake. Systematically organized approach must be implemented to perform crisis management at the national and global levels. To do so, Qazvin city in Iran was selected as a case to review and assess the vulnerability of 19 different regions.

Vulnerability analysis of the urban textures in Qazvin was then introduced in 19 urban districts based on 3 main criteria: "physical vulnerability," "texture responsiveness after crisis and relief possibility," and "city reversibility after crisis." In total, 20 subcriteria were studied and evaluated using Analytical Hierarchy Process (AHP). In order to perform a binary comparison between subcriteria, a questionnaire was designed and distributed to a group of field experts. The questionnaire results were further utilized in the AHP model.

Based on AHP results, it was concluded that, from 19 regions, 2 regions have high vulnerability (regions 10 and 18), 6 regions have moderate vulnerability (regions 3, 5, 11, 12, 13 and 15), and the remaining 11 regions have low vulnerability. "High population density," "area of old and repairable buildings," "shortage access to relief and medical services," "immigrants settled," "a few organic texture area," and "sidewalks with less than 6 meters width in the region" were identified as the most important causes of high vulnerability of urban textures in regions 10 and 18.

The AHP model for evaluating crisis management in this study shows that, in terms of urban management, crisis management is very important and all planning and preparations for crisis management are better to be done at this stage since human life and property are threatened in a short time. Anomalies and irregularities cover all levels of society because it leads (in most cases) to a problem exacerbated by the crisis and disaster. Therefore, managers and urban planners should develop a crisis management plan and framework based on the data and results of previous disasters to prevent the occurrence of human and financial losses in the future.

\section{Conflicts of Interest}

The authors declare that they have no conflicts of interest.

\section{References}

[1] K. Smith, Environmental Hazards: Assessing Risk and Reducing Disaster, Taylor \& Francis, Abingdon, UK, 4th edition, 2008.

[2] K. Hewitt, Regions of Risk. A Geographical Introduction to Disasters, Routledge, Abingdon, UK, 2014.
[3] J. Pathak, "Earthquake vulnerability assessment of Guwahati urban centre," in Proceedings of the 14th World Conference on Earthquake Engineering (WCEE'2008), Beijing, China, October 2008.

[4] S. Tyagunov, L. Stempniewski, G. Grünthal, R. Wahlström, and J. Zschau, "Vulnerability and risk assessment for earthquake prone cities," in Proceedings of the 13th World Conference on Earthquake Engineering (WCEE'08), Vancouver, BC, Canada, August 2008.

[5] Y. Aysan and I. Davis, "Rehabilitation and reconstruction," in Disasters and the Small Dwelling: Perspectives for the UN IDNDR, Routledge, Abingdon, UK, 2004.

[6] M. Abdollahi, Crisis Management in Urban Districts, National Municipalities Organization, Iran, 2004.

[7] P. R. Trim, "An integrative approach to disaster management and planning," Disaster Prevention and Management, vol. 13, no. 3, pp. 218-225, 2004.

[8] F. Nateghallahi, Seismic Vulnerability Quantitative Assessment in Reinforced Concrete Buildings Using Dynamic Nonlinear Analysis, International Institute of Earthquake Engineering and Seismology, Ministry of Science, Research and Technology, Tehran, Iran, 1998.

[9] H. Motohiko, "Earthquake in collection of experience," 2004.

[10] M. Hosseini, Crisis Management, Nashr e Shahr Institution, Tehran Disaster Mitigation and Management Organization, Tehran, Iran, 1st edition, 2009.

[11] A. Partovi, Urban Texture Vulnerability Evaluation in Natural Disasters and Effects Mitigation Methods, Khajeh Nasir Toosi University of Technology, Tehran, Iran, 2006.

[12] T. L. Saaty, "Decision making with the analytic hierarchy process," International Journal of Services Sciences, vol. 1, no. 1, pp. 83-98, 2008.

[13] M. R. Mehregan, Advanced Operational Research, Academic Books (Ketab-e-Daneshgahi), Tehran, Iran, 4th edition, 2008.

[14] E. W. Stein and A. Norita, "Using the analytical hierarchy process (AHP) to construct a measure of the magnitude of consequent of moral intensity," Journal of Business Ethics, vol. 89, no. 3, pp. 391-407, 2009.

[15] D. P. Coppola, Introduction to International Disaster Management, Butterworth-Heinemann, Elsevier, 3rd edition, Oxford, UK, 2015.

[16] S. H. Ghodsipour, Topics in Multi-Criteria Decision, vol. 3, Amirkabir University of Technology Press, Tehran, Iran, 2003. 


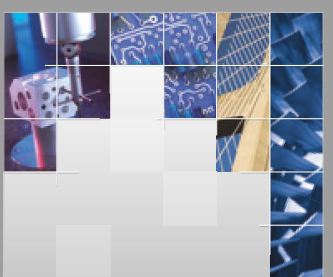

\section{Enfincering}


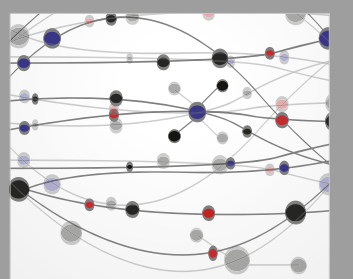

\section{Rotating \\ Machinery}

The Scientific World Journal

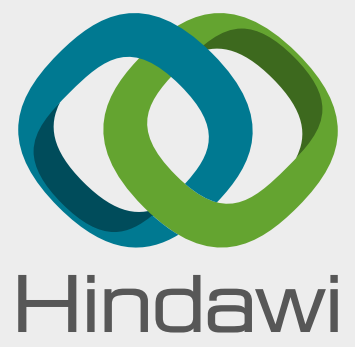

Submit your manuscripts at

www.hindawi.com
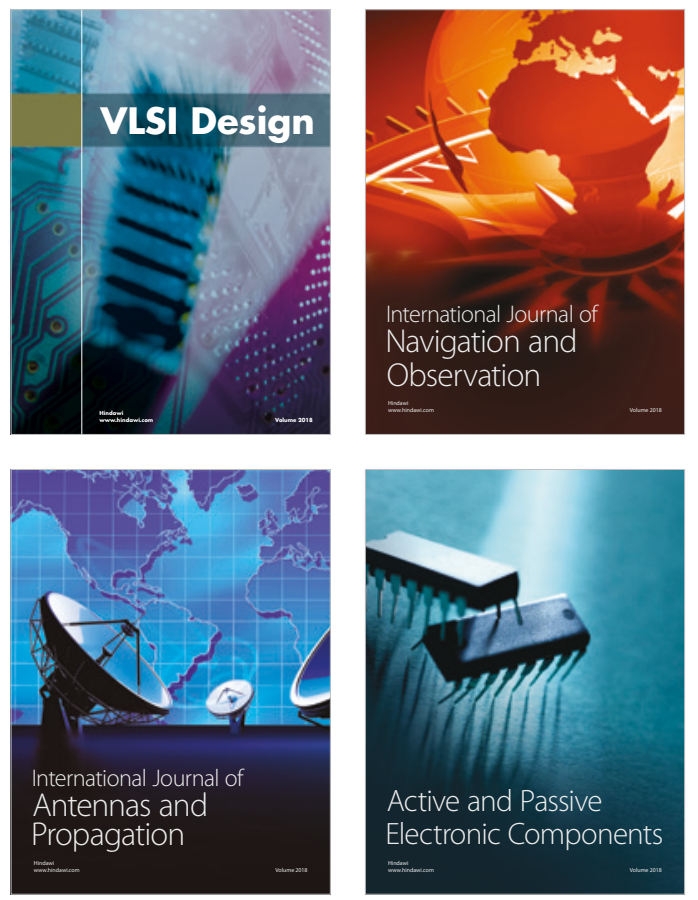
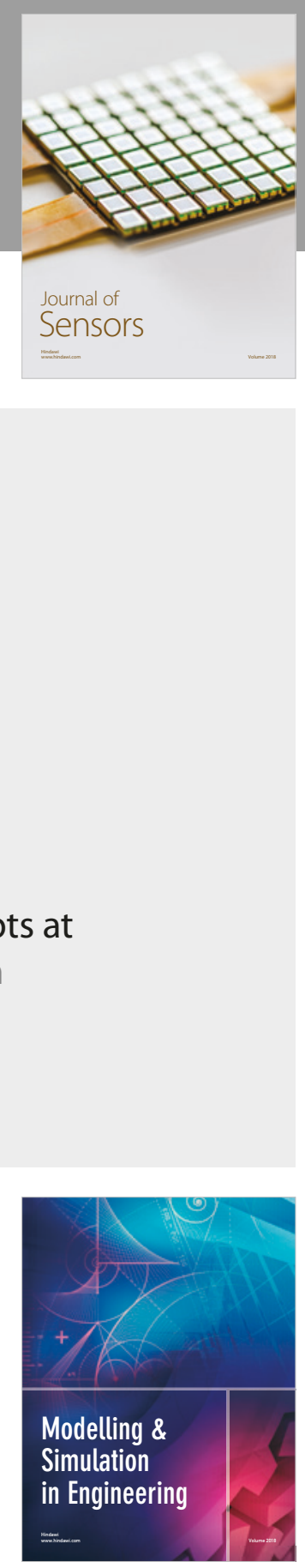

\section{Advances \\ Multimedia}
